OPEN ACCESS

Check for updates

\title{
Practice composition and sex differences in physician income: observational study
}

\author{
Christopher M Whaley, ${ }^{1}$ Daniel R Arnold, ${ }^{2}$ Nate Gross, ${ }^{3}$ Anupam B Jena $4,5,6$
}

${ }^{1}$ Rand, Santa Monica, CA, USA

${ }^{2}$ Department of Health Policy and Management, University of California, Berkeley, Berkeley,

CA, USA

${ }^{3}$ Doximity, San Francisco, CA, USA

${ }^{4}$ Department of Health Care Policy, Harvard Medical School, 180 Longwood Avenue, Boston, MA 02115, USA

${ }^{5}$ Massachusetts General Hospital, Boston, MA, USA

${ }^{6}$ National Bureau of Economic Research, Cambridge, MA, USA

Correspondence to: A B Jena jena@hcp.med.harvard.edu (or @AnupamBJena on Twitter: ORCID 0000-0002-9734-5122) Additional material is published online only. To view please visit the journal online.

Cite this as: $B M / 2020 ; 370: \mathrm{m} 2588$ http://dx.doi.org/10.1136/bmj.m2588 Accepted: 1 June 2020

\section{ABSTRACT}

OBJECTIVE

To assess whether differences in income between male and female physicians vary according to the sex composition of physician practices.

DESIGN

Retrospective observational study.

SETTING

US national survey of physician salaries, 2014-18.

\section{PARTICIPANTS}

18802 physicians from 9848 group practices

(categorized according to proportion of male

physicians $\leq 50 \%$, >50-75\%, >75-90\%, and $>90 \%$ ).

\section{MAIN OUTCOME MEASURES}

Sex differences in physician income in relation to the sex composition of physician practices after multivariable adjustment for physician specialty, years of experience, hours worked, measures of clinical workload, practice type, and geography.

\section{RESULTS}

Among 11490 non-surgical specialists, the absolute adjusted sex difference in annual income (men versus women) was $\$ 36604$ ( $£ 29663$; $€ 32621$ ) (95\% confidence interval $\$ 24903$ to $\$ 48306 ; 11.7 \%$ relative difference) for practices with $50 \%$ or less of male physicians compared with $\$ 91669$ (\$56587 to $\$ 126571 ; 19.9 \%$ relative difference) for practices with at least $90 \%$ of male physicians $(P=0.03$ for difference). Similar findings were observed among surgical specialists $(n=3483)$, with absolute adjusted sex difference in annual income of \$46503 (\$42198 to $\$ 135205 ; 10.2 \%$ relative difference) for practices with $50 \%$ or less of male physicians compared with $\$ 149460$ (\$86040 to $\$ 212880 ; 26.9 \%$ relative difference) for practices with at least $90 \%$ of male physicians ( $\mathrm{P}=0.06$ for difference). Among primary care physicians $(n=3829)$, sex differences in income were not related to the proportion of male physicians in a practice.

\section{WHAT IS ALREADY KNOWN ON THIS TOPIC}

Differences in income between male and female physicians are well known

The relation between workplace diversity and sex differences in physician income has not been investigated, despite evidence in other industries that greater sex diversity is associated with reduced sex differences in income

\section{WHAT THIS STUDY ADDS}

Sex differences in income were present across all specialties and among both non-surgical and surgical specialists

Sex differences in income were largest in practices with the highest proportion of physicians who were male, even after adjustment for factors that might explain sex differences in income

\section{CONCLUSIONS}

Among both non-surgical and surgical specialists, sex differences in income were largest in practices with the highest proportion of male physicians, even after detailed adjustment for factors that might explain sex differences in income.

\section{Introduction}

Differences in income between male and female physicians are well known. Among physicians overall, sex differences in income persist even after adjustment for specialty choice, hours worked, years of experience, and family structure. ${ }^{1-9}$ Among academic physicians, sex differences in income persist after adjustment for factors such as age, marital status, race, years of experience, specialty, work hours, research productivity, and faculty rank. ${ }^{10-16}$ Differences in income are not supported by differences in clinical quality. ${ }^{17-20}$

Although multiple factors influence sex differences in physician income, one area that has received little empirical investigation is the role of sex diversity in the workplace. Outside of healthcare, increased workplace sex diversity, a reduction in occupational segregation, and an increase in the proportion of female managers has been associated with reduced sex differences in income and smaller sex based wage gaps. ${ }^{21} 22$ Workplace diversity has been linked to greater worker productivity, ${ }^{23}$ and sex diversity has been linked to large productivity gains in knowledge intensive industries. $^{24}$

Within healthcare, greater representation of female physicians could also be associated with reduced sex differences in income. For example, female physicians are less likely to have mentors than their male counterparts, partially because of a difficulty in identifying mentors and an underrepresentation of female mentors in leadership positions, which might limit career advancement and contribute to sex differences in income. ${ }^{25}{ }^{26}$ Salary and other job negotiations might also be more challenging for female physicians in instances when the composition of employers is overwhelmingly male.

Whether greater sex diversity in physician practices is associated with reduced sex differences in physician income is unknown. Using uniquely linked salary and practice composition data on nearly 19000 physicians between 2014 and 2018, we analyzed whether the sex composition of physician group practices was associated with sex differences in physician income, hypothesizing that sex differences in income might be larger in heavily male dominated practices than in those with a more equal distribution of male and female physicians, even after adjusting for physician 
specialty, years of experience, hours worked, measures of clinical workload, and geography.

\section{Methods}

Physician compensation in the US

US physicians are typically compensated in one of several ways: fully salaried, fully tied to clinical revenue that is generated, or some combination of the two. In publicly funded clinics, compensation is typically set by a fixed salary, which might vary with years of experience, clinical specialty, local market rates, and other factors. In privately owned organizations, including for profit and not-for-profit hospitals and group practices, compensation might be set by either a fixed salary, according to clinical revenue that is generated, or a combination of the two. For example, in academic and non-academic settings it is possible that physicians have a fixed salary on top of which bonuses could be paid that are a function of the amount of clinical revenue that a physician generates through either the types or number of procedures performed or the number of patients seen. Similarly, in private practice settings, a fixed salary plus bonus structure could occur or compensation that is completely tied to clinical revenue. An additional factor that influences income is that some physicians own partnership interest in practices such that their total income also includes compensation for overhead costs (sometimes called facility fees). Negotiations that occur between physicians and the employing practices might concern the time required to gain partnership and the monetary amount required for investment. With the exception of settings when the salary is publicly determined and additional negotiation is not possible, sex differences in income might arise across physicians owing to differences in underlying compensation negotiations.

\section{Physician characteristics, income, and group practice composition}

We obtained data on physician characteristics from Doximity, an online platform for physicians. The platform includes more than one million members and more than $70 \%$ of US physicians. ${ }^{27}$ Doximity has collected information on physician characteristics for both registered members and non-registered physicians through multiple sources and data partnerships, including the National Plan and Provider Enumeration System (NPPES), National Provider Identifier Registry, the American Board of Medical Specialties, state licensing boards, specialty societies, and collaborating medical schools and hospitals. The database includes information on physician age, sex, specialty, medical school attended (name and type of training, ie, allopathic or osteopathic), years in practice, and practice location. Details and validation of the database are described elsewhere. ${ }^{1728-32}$

We obtained data on annual incomes from Doximity, which since 2014 has conducted an ongoing survey of physician income. ${ }^{33}$ Since 2014, 102129 physicians have completed the compensation survey, providing information on annual income, practice type (eg, hospital or group practice), and average hours worked each week. After limiting responses to full time physicians with valid national provider identifiers and limiting to the 2014-18 period of our data on physician practice structure, 68099 physician responses overlapped. Income was reported in categories with increments of $\$ 5000$ ( $€ 4057$; €4445) between $\$ 40000$ and $\$ 250000$ and increments of $\$ 25000$ between $\$ 250000$ and $\$ 1000000$. We linked income to data on physician characteristics using each physician's national provider identifier. In all analyses, we modeled income as a continuous variable, in which the specific income for a physician was the top value within each income category.

Information on practice composition was obtained for 2014-18 from the SK\&A office based physicians' database provided by IQVIA, a commercial database of healthcare providers ${ }^{3435}$ that provides a nearly complete sampling frame of US office based physicians ( $>95 \%$ coverage according to IQVIA). ${ }^{36}$ A group of academic researchers concluded the database captures about $75 \%$ of US physicians. ${ }^{37}$ Data in the SK\&A database are collected through a national survey of physicians and their group practice affiliations. The database contains unique practice identifiers for each physician, which we used to link individual physicians with available information on salary to other physicians in the same practice group or system using physician national provider identifier. Not all physicians with income data were surveyed in the SK\&A database and vice versa. Because some physicians might report several practice affiliations, we used the primary affiliation reported in the SK\&A database to link physicians to groups.

\section{Statistical analysis}

Our goal was to study whether differences in income between male and female physicians were related to the sex composition of groups in which these physicians practice.

Analysis was limited to groups with a minimum of five physicians (see supplemental file for sensitivity analysis without this cut-off) and to physicians who reported practicing full time and working at least 40 hours a week. Overall, 18802 physicians (from 9848 group practices) were in both the compensation and the SK\&A databases and met the inclusion criteria. We divided physicians into three specialty categoriesprimary care physicians, non-surgical specialists (eg, cardiologists, radiologists), and surgical specialists (eg, general and orthopedic surgeons). The supplemental file includes a flow diagram and detailed specialty list.

For each physician with information on income, we used SK\&A data to compute within each group the share of physicians who were male. Then, within each of the specialty categories and for physicians overall, we categorized practices into four groups based on the proportion of male physicians $(\leq 50 \%,>50-75 \%$, $>75-90 \%$, and $>90 \%$ ). These categories approximately corresponded to quarters among physicians overall and were selected to be the same across specialty groupings for ease of interpretation. To allow for a non- 
linear relation between the per cent of physicians in a practice that are male and sex differences in income, we modeled the sex composition of practices as a categorical variable.

Multivariable models were used to examine differences in income between male and female physicians across groups of varying male practice share. We estimated a multivariable generalized linear model with a log link and gamma distributed error term of physician income (dependent variable) as a function of physician level covariates, including years since medical school graduation, number of hours worked a week, and the annual amount billed to Medicare during 2014 to 2016, obtained from the Centers for Medicare and Medicaid Services, the last two variables accounting for potential physician sex differences in hours worked and clinical workload; indicator variables for each physician's detailed specialty; practice covariates, including number of physicians in the practice and an indicator variable for whether the practice was owned by a hospital or health system; metropolitan statistical area indicator variables to adjust for time invariant geographic factors that might be associated with sex differences in physician income; and an interaction term between the category of the male physician practice share and an indicator variable for female physician. The model estimated the average, adjusted difference in income between male and female physicians in each of four categories of practice share by male physician. To allow for a non-linear relation with sex differences in income, we treated the practice share by male physicians as a categorical variable. Log link models were chosen to account for known skewness in income, ${ }^{38}$ and we calculated adjusted sex differences in income using the marginal standardization form of predictive margins. ${ }^{39}$ Robust standard errors were clustered at the practice level.

Our analysis involved a between practice rather than a within practice statistical design, such that we compared sex differences in physician income between male and female physicians working in different practices that varied in proportion of male physicians rather than within the same practice. Although a within practice study design would adjust for practice invariant characteristics that are correlated with both overall salaries and male physician practice share, such a design was not possible given the limited number of physician practices with available information on salary for both male and female physicians.

\section{Sensitivity analyses}

We conducted several sensitivity analyses. First, we estimated models in which the share of male physicians in a practice was treated as a continuous, rather than a categorical, variable. Second, we estimated models using multivariable linear regression rather than a generalized linear model. Third, a concern with our empirical approach is that female physicians who are selected for predominantly male practices might differ in unobserved ways that are correlated with income compared with female physicians who are selected for predominantly female practices (eg, they might not have children or might have different work preferences), even after accounting for the variables described previously. ${ }^{40}$ In this case, the relation between the share of male physicians in a practice and sex differences in physician income would be biased by unmeasured confounders. To tackle this concern, we performed two tests. First, we weighted the sample to be representative of the US physician workforce (see supplemental file for methods). Second, we estimated sex differences in physician income according to male practice share without adjusting for other physician or practice covariates (ie, an unadjusted analysis), under the assumption that the observed covariates in our model would likely be correlated with any unmeasured confounders. Finding a similar adjusted and unadjusted relation between sex differences in physician income and the proportion of male physicians in a practice might suggest that unmeasured confounding is unlikely to be important. A similar concern is that adjusting for Medicare patient workload might capture differences in patient composition between patients with public insurance coverage and those with private sources of insurance coverage, which given the structure of physician payments in the US could account for observed differences in income. We therefore conducted a sensitivity analysis that excluded the Medicare workload covariate from the multivariable regression. Finally, we estimated separate models for physicians employed by academic and non-academic institutions, under the assumption that sex differences in income might be smaller for academic physicians.

Analysis was performed using Stata, version 16.

\section{Patient and public involvement}

No patients were involved in setting the research question or the outcome measures, nor were they involved in developing plans for design or implementation of the study, primarily because of author resource constraints in soliciting this input, the statistical methodology and software required for answering the research question, and the proprietary nature of the secondary data.

\section{Results}

\section{Characteristics of study population}

Overall, 18802 physicians were analyzed, of whom 3829 (20.4\%) were primary care physicians, 11490 $(61.1 \%)$ were non-surgical specialists, and 3483 (18.5\%) were surgical specialists (table 1). The mean annual income was \$376223 (\$252872 among primary care physicians, $\$ 374774$ among non-surgical specialists, and \$516608 among surgical specialists).

The mean number of physicians in a group was 18.1 for primary care physicians, 24.0 for non-surgical specialists, and 20.3 for surgical specialists (see supplemental figure S2 for distribution of group size). Mean years since graduation from medical school were similar across specialty categories (primary care 


\begin{tabular}{|c|c|c|c|}
\hline Characteristics & Primary care physicians $(n=3829)$ & $\begin{array}{l}\text { Non-surgical specialists } \\
(\mathrm{n}=11490)\end{array}$ & Surgical specialists $(n=3483)$ \\
\hline Mean (SD) income (\$) & $252872(89455)$ & $374774(164064)$ & 516608 (216991) \\
\hline Median (interquartile range) income (\$) & $27499(224999-324999)$ & 399999 (299999-499999) & $499999324999-674999$ \\
\hline Women & $33.6(1286)$ & $22.7(2710)$ & $9.2(320)$ \\
\hline Mean (SD) practice size (No of physicians) & $18.1(-33.3)$ & $24.0(-48.3)$ & $20.3(-47.8)$ \\
\hline \multicolumn{4}{|l|}{ Practice size (No of physicians): } \\
\hline 5-10 & $57.8(2210)$ & $46.2(5304)$ & $58.9(2050)$ \\
\hline $11-20$ & $21.3(817)$ & $26.4(3036)$ & $23.7(827)$ \\
\hline$>20$ & $20.9(802)$ & $27.4(3150)$ & $17.4(606)$ \\
\hline Mean (SD) Medicare allowed amount, total (\$) & $73798(79523)$ & $136991(278009)$ & $131931(142370)$ \\
\hline Mean (SD) years since medical school graduation & $20.8(10.1)$ & $22.5(9.9)$ & $21.4(9.7)$ \\
\hline Mean (SD) weekly hours worked & $53.8(11.5)$ & $58.7(12.2)$ & $65.3(13.3)$ \\
\hline \multicolumn{4}{|l|}{ Census region: } \\
\hline North east & $19.6(750)$ & $22.9(2631)$ & $21.4(745)$ \\
\hline Midwest & $23.5(900)$ & $23.7(2723)$ & $23.9(832)$ \\
\hline South & $32.0(1225)$ & $32.3(3711)$ & $33.8(1177)$ \\
\hline West & $24.9(953)$ & $21.1(2424)$ & $20.9(728)$ \\
\hline
\end{tabular}

$\$ 1.00(f 0.81 ; € 0.89)$

2014-18 data were from Doximity, 2014-18 data from SK\&A office based physicians' database (now IQVIA), and 2014-16 data from Centers for Medicare and Medicaid Services' Medicare physician and other supplier data. Primary care physician specialties included: family medicine $(n=1362)$, geriatric medicine $(n=153)$, internal medicine $(n=1194)$, medicine/pediatrics $(n=84)$, occupational medicine $(n=13)$, other allopathic/osteopathic medicine $(n=17)$, pediatric emergency medicine $(n=958)$, pediatric medicine $(n=30)$, and preventive medicine ( $n=5)$. Surgical specialists included. colon and rectal surgery $(n=84)$, general surgery $(n=687)$, neurosurgery $(n=277)$, oral and maxillofacial surgery ( $n=3)$, orthopedic surgery $(n=1111)$, plastic surgery ( $n=131)$, thoracic surgery $(n=176)$, urology $(n=363)$, and vascular surgery $(n=183)$. Physicians with specialties not already listed were considered non-surgical specialists. The five largest specialties among non-surgical specialists were anesthesiology $(n=1481)$, cardiology $(n=1204)$, radiology $(n=989)$, obstetrics and gynecology $(n=907)$, and psychiatry $(n=402)$.

physicians, 20.8 years; non-surgical specialists, 22.5 years; surgical specialists, 21.4 years). On average, physicians reported working 58.9 hours a week, with primary care physicians reporting working on average 53.8 hours a week compared with 58.7 hours for non-surgical specialists and 65.3 hours for surgical specialists.

\section{Distribution of male physicians across group practices}

Among primary care physicians, on average $66.4 \%$ of physicians were male (fig 1) and 32.4\% worked in practices with $50 \%$ or less of men, $47.8 \%$ in practices with $>50-75 \%, 15.0 \%$ in practices with $>75-90 \%$, and $4.8 \%$ in practices with at least $90 \%$. Among non-surgical specialists, on average $77.3 \%$ of physicians were male and 14.3\%, 38.0\%, 30.2\%, and $17.5 \%$ worked in practices with $50 \%$ or less, $>50$ $75 \%,>75-90 \%$, and at least $90 \%$ of male physicians, respectively. Among surgical specialists, on average $90.8 \%$ of physicians were male and the respective practice shares were $2.0 \%, 18.7 \%, 34.9 \%$, and $44.4 \%$.

\section{Practice composition and sex differences in physician income}

Mean annual income was larger among male physicians, even after adjustment for covariates (unadjusted income for men $\$ 402540$, and for women $\$ 285121$, difference $\$ 117419$; adjusted income for men $\$ 394139$, and for women $\$ 314269$, difference $\$ 79871$ (95\% confidence interval \$78126 to \$81 615).

The relation between sex differences in income and the share of physicians in a practice who were male varied according to specialty (fig 2). For example, among primary care physicians, women reported lower income than men, but no relation was observed between sex differences in adjusted income and the share of physicians in a practice who were male (fig 2, panel A). Among non-surgical specialists and surgical specialists, however, sex differences in adjusted income were largest in practices with a high share of male physicians. For instance, among nonsurgical specialists (fig 2, panel B), the adjusted sex difference in income was \$36604 (95\% confidence interval $\$ 24903$ to $\$ 48306$ ) for practices with $50 \%$ or less of male physicians (11.7\% relative difference), $\$ 40653$ (\$33418 to $\$ 47889$ ) for practices with $>50-75 \%$ (12.6\% relative difference), and $\$ 29901$ (\$17107 to $\$ 42695$ ) for practices with $>75-90 \%$ (7.3\% relative difference), compared with $\$ 91669$ (\$56587 to \$126751) for practices with at least 90\% of male physicians (19.9\% relative difference). In a test of interactions, sex differences in income were significantly different for practices with at least $90 \%$ of male physicians compared with practices with $50 \%$ or less, $>50-75 \%$, and $>75-90 \%(\mathrm{P}<0.01, \mathrm{P}=0.01$, and $\mathrm{P}<0.01$, respectively).

Among surgical specialists, sex differences in income also increased with the proportion of male physicians in a practice (fig 2, panel C). The adjusted sex difference in income was a non-statistically significant \$46503 (-\$42198 to \$135205) for practices with $50 \%$ or less of male physicians $(10.2 \%$ relative difference), $\$ 44666$ (\$13659 to $\$ 75763$ ) for practices with $>50-75 \%$ (9.3\% relative difference), and $\$ 76958$ (\$49060 to $\$ 104858$ ) for practices with $>75-90 \%$ (15.1\% relative difference), compared with $\$ 149460$ (\$86040 to $\$ 212880$ ) for practices with at least $90 \%$ of male physicians $(26.9 \%$ relative difference). In a test of interactions, sex differences in income were significantly different in practices with at least $90 \%$ of male physicians compared with practices with $50 \%$ or less, $>50-75 \%$, and $>75-90 \%(P=0.06$, $\mathrm{P}=0.03$, and $\mathrm{P}=0.04$, respectively). 


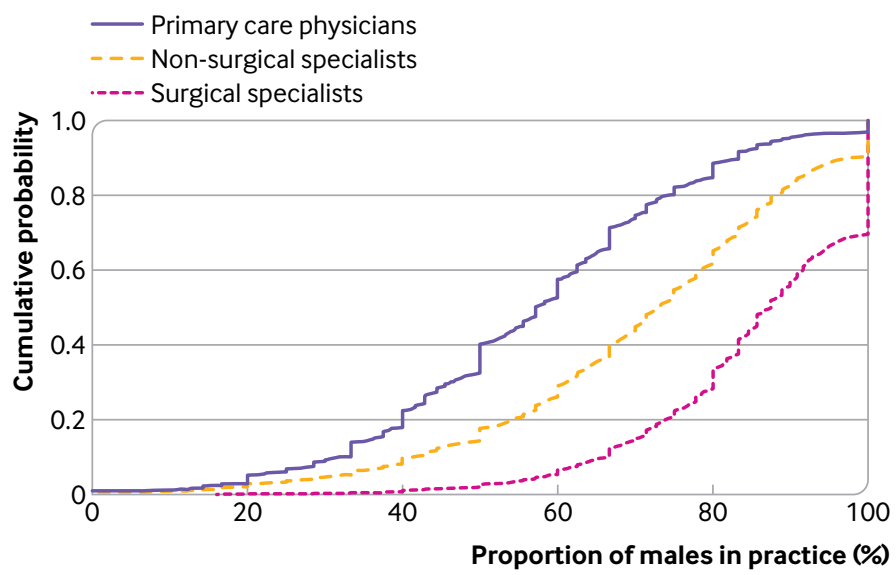

Fig 1 | Distribution of practices according to proportion of male physicians, by specialty. 2014-18 data from SK\&A office based physicians' database (now IQVIA)

\section{Sensitivity analyses}

Similar findings were observed when we treated the share of male physicians in a practice as a continuous variable and estimated multivariable linear models. Findings were also unchanged by using alternative thresholds of group practice size, weighting results to be representative of the US physician population, comparing academic and non-academic physicians, and excluding the Medicare clinical workload covariate. Finally, similar findings were observed when comparing unadjusted and adjusted relations between male practice share and sex differences in income, an analysis intended to examine potential bias due to unmeasured confounders (see supplemental file).

\section{Discussion}

In this study we linked data on physician salaries to the sex composition of group practices and found that among non-surgical and surgical specialists, sex differences in income were largest in those practices with the highest proportion of male physicians, a pattern that was present even after adjustment for full time status, hours worked, measures of clinical workload, years in practice, practice ownership, and geography.

The sex differences in specialist income that were observed in predominantly male practices were large. For example, among surgical specialists who worked in practices with at least $90 \%$ of male physicians, male physicians earned $\$ 149460$ more a year than female physicians (relative difference $26.9 \%$ ), even after adjustment for full time status, hours worked, measures of clinical workload, years in practice, practice ownership, and geography. In contrast, among surgical specialists who worked in practices with 50\% or less of male physicians (ie, the sex distribution of physicians was more equal), male physicians earned $\$ 46503$ more a year than female physicians (relative difference 10.2\%).

Among surgical specialists, $22 \%$ of the difference in income between male and female physicians was explained by differences in the sex composition of the practices. In other words, if sex differences in income were held at the level observed for practices with $50 \%$ or less of male physicians, the overall income gap for female physicians that has been observed in other studies would be $22 \%$ lower, if our findings are causal. Similarly, among non-surgical specialists, 7\% of the difference in income between male and female physicians was explained by sex differences in income based on the practice share of male physicians.

The observation that sex differences in specialist income were largest in predominantly male practices could be due to several factors. First, residual confounders might be correlated with both practice choice and sex differences in income, even after adjusting for specialty, full time status, hours worked, measures of clinical workload, years in practice, practice ownership, and geography. However, these unmeasured confounders would not only need to differ between men and women but would need to differ between the women who practice in predominantly male versus more balanced groups.

Second, our findings could be partly explained by implicit or explicit bias against women in predominantly male practices. Substantial evidence shows that bias exists, including female physicians being less likely to be referred to as a doctor, ${ }^{41}$ and among academic physicians, disparities in promotion, receipt of large grants, start-up packages, mentor involvement, and leadership opportunities. ${ }^{28} 42-44$ More than 30\% of female physicians also report having experienced sexual harassment or sex discrimination..$^{45} 46$ It is possible that the large sex differences in specialist income that we observed in predominantly male practices partly stems from these systemic issues.

Third, our findings could be explained by differences in how female specialists in predominantly male practices negotiate income. In many group practices, income has a variable component that is not fully linked to clinical workload, which could lead to sex differences in income if bargaining power is lower among female physicians working in predominantly male practices. Even in practices where income is closely tied to clinical workload, partnership opportunities (the probability of partnership, cost of becoming a partner, and time to partnership) might differ between male and female physicians, and those differences might be larger in predominantly male practices. Future work should examine the extent to which physician compensation structure leads to the observed disparities.

Fourth, previous work has suggested that women in predominantly male practices might receive fewer patient referrals, or receive referrals for less profitable patients. ${ }^{47}$ Although our analysis adjusted for each physician's total Medicare billing, we were unable to adjust for billing to commercial payers or patient profitability. Examining the patient impacts of differential referral patterns that potentially lead to differences in compensation is important for future studies. 

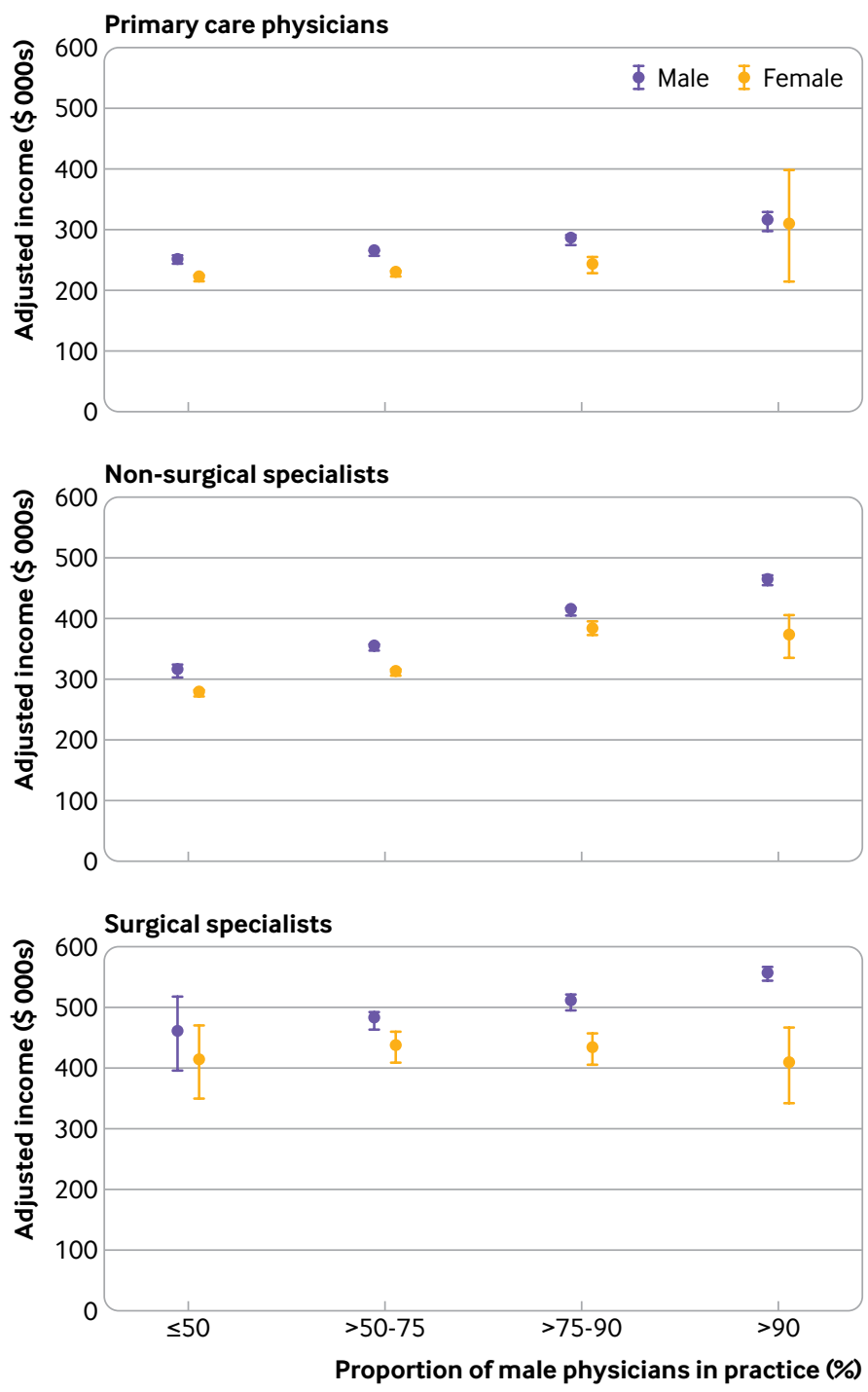

Fig 2 | Sex differences in adjusted income according to proportion of male physicians in a practice, by specialty. 2014-18 data from Doximity, 2014-18 data from SK\&A office based physicians' database (now IQVIA), and 2014-16 data from Centers for Medicare and Medicaid Services' Medicare physician and other supplier data. Figure plots adjusted incomes of male physicians and female physicians according to proportion of male physicians in a practice. Adjusted incomes were obtained from a generalized linear model of income as a function of physician, practice, and geographic characteristics, estimated separately for each specialty type. Whiskers represent $95 \%$ confidence intervals achieve more sex balance. From the individual physician perspective, our results, if causal, suggest that female specialists might benefit financially from working in practices with a larger proportion of female colleagues. Female specialists who work in predominantly male practices might also benefit from salary transparency or access to salary benchmarks to ensure that their compensation aligns with that of their male counterparts. Additional studies are needed to assess whether salary transparency might lessen the compensation gap for female physicians.

\section{Limitations of this study}

Our study has limitations. First, as the study was observational, unmeasured confounders could be correlated with both practice choice and sex differences in income. Physicians self-select into groups and it is possible that female specialists with lower earnings expectations self-select into predominantly male groups. However, we observed similar findings in both unadjusted and adjusted analyses, suggesting that unmeasured confounding might be less likely to the extent that confounders, if present, would be expected to be correlated with observed physician covariates. We also observed similar relations when excluding adjustment for Medicare clinical workload, suggesting that our findings were not explained by differences in patient composition. Second, income data were self-reported and might be subject to measurement error. Relatedly, because income data were self-reported it is possible that male physicians over-estimated annual income compared with female physicians. This should not affect our analysis if any sex differences in income estimation do not vary according to the sex composition of physicians' practices. Third, our income data, although the largest of its kind to date and geographically diverse, were not nationally representative. However, any differences in mean income compared with nationally representative income data should not bias an analysis of how sex differences in income vary according to the predominance of male physicians in a practice. In addition, in our sensitivity tests we observed similar results when weighting the sample to be nationally representative. Fourth, our analysis could not identify the mechanisms behind larger sex differences in specialist income in practices that were predominantly male. Fifth, our approach to classifying the sex composition of practices was based on the count of male and female physicians within a practice, as opposed to the share of total full time equivalents, represented by male versus female physicians (eg, a practice with a one full time equivalent male physician and four 0.25 full time equivalent female physicians was classified as one fifth male as opposed to one half male based on full time equivalents).

\section{Conclusions}

When we linked data on physician salaries to the sex composition of group practices, we found that among non-surgical and surgical specialists, sex differences 
in income were largest in those practices that were predominantly male, even after adjustment for factors that might explain sex differences in income. Our findings are consistent with the hypothesis that greater diversity in the workplace could help to deal with disparities in income.

Contributors: All authors contributed to the design and conduct of the study, data collection and management, analysis and interpretation of the data; and preparation, review, or approval of the manuscript. $A B$ J supervised the study and is the guarantor. The corresponding author attests that all listed authors meet authorship criteria and that no others meeting the criteria have been omitted. Funding: $A B$ J was supported by the Office of the Director, National Institutes of Health (1DP5OD017897), CMW was supported by the National Institutes on Aging (1K01AG061274), and DRA was supported by the Nicholas C Petris Center on Health Care Markets and Consumer Welfare. The research conducted was independent of any involvement from the sponsors of the study. The study sponsors were not involved in study design, data interpretation, writing, or the decision to submit the article for publication.

Competing interests: All authors have completed the ICMJE uniform disclosure form at www.icmje.org/coi_disclosure.pdf and declare: external funding support from the National Institutes on Aging (1K01AG061274) to CMW, the Nicholas C Petris Center on Health Care Markets and Consumer Welfare to DRA, and the Office of the Director, National Institutes of Health (1DP5OD017897) to ABJ; no financial relationships with any organizations that might have an interest in the submitted work in the previous 3 years; and no other relationships or activities that could appear to have influenced the submitted work; $A B$ J reports receiving consulting fees unrelated to this work from Pfizer, Hill Rom Services, Bristol Myers Squibb, Novartis, Amgen, Eli Lilly, Vertex Pharmaceuticals, AstraZeneca, Celgene, Tesaro, Sanofi Aventis, Biogen, Precision Health Economics, and Analysis Group; CMW reports consulting fees unrelated to this paper from Doximity; DRA reports consulting fees unrelated to this paper from the Rhode Island Department of Health; NG reports being employed by and holding stock in Doximity.

Ethical approval: This study was approved by the institutional review boards at Harvard Medical School and at Rand.

Data sharing: No additional data available.

$A B J$ affirms that the manuscript is an honest, accurate, and transparent account of the study being reported; that no important aspects of the study have been omitted; and that any discrepancies are disclosed.

Dissemination to participants and related patient and public communities: The results of this work will be disseminated to the public through institutional press release, ensuing news articles, and an opinion piece authored by the study's authors that describe the study's findings for the public.

This is an Open Access article distributed in accordance with the Creative Commons Attribution Non Commercial (CC BY-NC 4.0) license, which permits others to distribute, remix, adapt, build upon this work non-commercially, and license their derivative works on different terms, provided the original work is properly cited and the use is non-commercial. See: http://creativecommons.org/licenses/ by-nc/4.0/.

1 Baker LC. Differences in earnings between male and female physicians. N Engl J Med 1996;334:960-4. doi:10.1056/ NEJM199604113341506

2 Lo Sasso AT, Richards MR, Chou CF, Gerber SE. The \$16,819 pay gap for newly trained physicians: the unexplained trend of men earning more than women. Health Aff (Millwood) 2011;30:193-201. doi:10.1377/hlthaff.2010.0597

3 Seabury SA, Chandra A, Jena AB. Trends in the earnings of male and female health care professionals in the United States, 1987 to 2010. JAMA Intern Med 2013;173:1748-50. doi:10.1001/ jamainternmed.2013.8519

4 Hoff TJ. Doing the same and earning less: male and female physicians in a new medical specialty. Inquiry 2004;41:301-15. doi:10.5034/ inquiryirnl 41.3.301

5 Ly DP, Seabury SA, Jena AB. Differences in incomes of physicians in the United States by race and sex: observational study. BMJ 2016;353:i2923. doi:10.1136/bmj.i2923

6 Frintner MP, Sisk B, Byrne BJ, Freed GL, Starmer AJ, Olson LM. Gender Differences in Earnings of Early- and Midcareer Pediatricians. Pediatrics 2019;144:e20183955. doi:10.1542/peds.2018-3955
7 Wiler JL, Rounds K, McGowan B, Baird J. Continuation of Gender Disparities in Pay Among Academic Emergency Medicine Physicians. Acad Emerg Med 2019;26:286-92. doi:10.1111/acem.13694

8 Apaydin EA, Chen PGC, Friedberg MW. Differences in Physician Income by Gender in a Multiregion Survey. J Gen Intern Med 2018:33:1574-81. doi:10.1007/s11606-018-4462-2

9 Nguyen Le TA, Lo Sasso AT, Vujicic M. Trends in the earnings gender gap among dentists, physicians, and lawyers. J Am Dent Assoc 2017:148:257-262.e2. doi:10.1016/j.adaj.2017.01.005

10 Jagsi R, Griffith KA, Stewart A, Sambuco D, DeCastro R, Ubel PA. Gender differences in the salaries of physician researchers. JAMA 2012;307:2410-7. doi:10.1001/jama.2012.6183

11 Jagsi R, Griffith KA, Stewart A, Sambuco D, DeCastro R, Ubel PA. Gender differences in salary in a recent cohort of early-career physician-researchers. Acad Med 2013;88:1689-99. doi:10.1097/ ACM.0b013e3182a71519

12 Ash AS, Carr PL, Goldstein R, Friedman RH. Compensation and advancement of women in academic medicine: is there equity?Ann Intern Med 2004;141:205-12. doi:10.7326/0003-4819-141-3200408030-00009

13 Weeks WB, Wallace TA, Wallace AE. How do race and sex affect the earnings of primary care physicians? Health Aff (Millwood) 2009;28:557-66. doi:10.1377/hlthaff.28.2.557

14 Ness RB, Ukoli F, Hunt S, et al. Salary equity among male and female internists in Pennsylvania. Ann Intern Med 2000;133:104-10. doi:10.7326/0003-4819-133-2-200007180-00009

15 DesRoches CM, Zinner DE, Rao SR, lezzoni LI, Campbell EG. Activities, productivity, and compensation of men and women in the life sciences. Acad Med 2010;85:631-9. doi:10.1097/ ACM.0b013e3181d2b095

16 Jena AB, Olenski AR, Blumenthal DM. Sex Differences in Physician Salary in US Public Medical Schools. JAMA Intern Med 2016;176:1294-304. doi:10.1001/ jamainternmed.2016.3284

17 Tsugawa Y, Jena AB, Figueroa JF, Orav EJ, Blumenthal DM, Jha AK. Comparison of Hospital Mortality and Readmission Rates for Medicare Patients Treated by Male vs Female Physicians. JAMA Intern Med 2017;177:206-13. doi:10.1001/jamainternmed.2016.7875

18 Roter DL, Hall JA, Aoki Y. Physician gender effects in medical communication: a meta-analytic review. JAMA 2002;288:756-64. doi:10.1001/jama.288.6.756

19 Kim C, McEwen LN, Gerzoff RB, et al. Is physician gender associated with the quality of diabetes care?Diabetes Care 2005;28:1594-8. doi:10.2337/diacare.28.7.1594

20 Baumhäkel M, Müller U, Böhm M. Influence of gender of physicians and patients on guideline-recommended treatment of chronic heart failure in a cross-sectional study. Eur J Heart Fail 2009;11:299-303. doi:10.1093/eurjhf/hfn041

21 Chattopadhyay P, Tluchowska M, George E. Identifying the ingroup: A closer look at the influence of demographic dissimilarity on employee social identity. Acad Manage Rev 2004;29:180-202. doi:10.5465/ amr.2004.12736071

22 Joshi A, Liao H, Jackson SE. Cross-Level Effects of Workplace Diversity on Sales Performance and Pay. Acad Manage J 2006;49:459-81. doi:10.5465/amj.2006.21794664

23 Hamilton $\mathrm{BH}$, Nickerson JA, Owan H. Diversity and Productivity in Production Teams. In: Bryson A, ed. Advances in the Economic Analysis of Participatory and Labor-Managed Firms. Emerald Group Publishing, 2012: 99-138. doi:10.1108/S08853339(2012)0000013009

24 Garnero A, Kampelmann S, Rycx F. The Heterogeneous Effects of Workforce Diversity on Productivity, Wages, and Profits. Ind Relat 2014:53:430-77. doi:10.1111/irel.12064

25 Butkus R, Serchen J, Moyer DV, Bornstein SS, Hingle ST, Health and Public Policy Committee of the American College of Physicians. Achieving Gender Equity in Physician Compensation and Career Advancement: A Position Paper of the American College of Physicians. Ann Intern Med 2018;168:721-3. doi:10.7326/M17. 3438.

26 Reisman AB, Gross CP. Gender differences in the ability to identify a mentor at morning report: a multi-institutional survey. Teach Learn Med 2002;14:236-9. doi:10.1207/S15328015TLM1404_6

27 Doximity. Doximity Reaches 70 Percent of All U.S. Doctors, More than 800000 Licensed Medical Professionals, 2017.

28 Jena AB, Khullar D, Ho O, Olenski AR, Blumenthal DM. Sex Differences in Academic Rank in US Medical Schools in 2014 IAMA 2015;314:1149-58. doi:10.1001/jama.2015.10680

29 Jena AB, Olenski AR, Blumenthal DM. Sex Differences in Physician Salary in US Public Medical Schools. JAMA Intern Med 2016;176:1294-304. doi:10.1001/ jamainternmed.2016.3284

30 Tsugawa Y, Jha AK, Newhouse JP, Zaslavsky AM, Jena AB. Variation in Physician Spending and Association With Patient Outcomes. JAMA Intern Med 2017;177:675-82. doi:10.1001/ jamainternmed.2017.0059 
31 Tsugawa Y, Newhouse JP, Zaslavsky AM, Blumenthal DM, Jena AB. Physician age and outcomes in elderly patients in hospital in the US: observational study. BMJ 2017;357:j1797. doi:10.1136/bmj. j1797

32 Khullar D, Blumenthal DM, Olenski AR, Jena AB. U.S. Immigration Policy and American Medical Research: The Scientific Contributions of Foreign Medical Graduates. Ann Intern Med 2017;167:584-6. doi:10.7326/M17-1304

33 Doximity. Career Navigator Survey: Doximity; 2019 www.doximity. com/careers accessed 10 June 2019.

34 Gresenz CR, Auerbach DI, Duarte F. Opportunities and challenges in supply-side simulation: physician-based models. Health Serv Res 2013;48:696-712. doi:10.1111/1475-6773.12029

35 Yasaitis LC, Pajerowski W, Polsky D, Werner RM. Physicians' Participation In ACOs Is Lower In Places With Vulnerable Populations Than In More Affluent Communities. Health Aff (Millwood) 2016;35:1382-90. doi:10.1377/hlthaff.2015.1635

36 Rhodes KV, Kenney GM, Friedman AB, et al. Primary care access for new patients on the eve of health care reform. JAMA Intern Med 2014;174:861-9. doi:10.1001/jamainternmed.2014.20

37 Baker LC, Bundorf MK, Devlin AM, Kessler DP. Hospital Ownership of Physicians: Hospital Versus Physician Perspectives. Med Care Res Rev 2018:75:88-99. doi:10.1177/1077558716676018

38 Manning WG, Mullahy J. Estimating log models: to transform or no to transform?) Health Econ 2001;20:461-94. doi:10.1016/S01676296(01)00086-8

39 Williams R. Using the margins command to estimate and interpret adjusted predictions and marginal effects. Stata / 2012;12:308-31 doi:10.1177/1536867X1201200209

40 Starmer AJ, Frintner MP, Matos K, Somberg C, Freed G, Byrne BJ. Gender Discrepancies Related to Pediatrician Work-Life Balance and Household Responsibilities. Pediatrics 2019;144:e20182926. doi:10.1542/peds.2018-2926

41 Files JA, Mayer AP, Ko MG, et al. Speaker Introductions at Interna Medicine Grand Rounds: Forms of Address Reveal Gender Bias. J Womens Health (Larchmt) 2017;26:413-9. doi:10.1089/ jwh.2016.6044

42 Blumenthal DM, Olenski AR, Yeh RW, et al. Sex Differences in Faculty Rank Among Academic Cardiologists in the United States. Circulation 2017;135:506-17. doi:10.1161/ CIRCULATIONAHA.116.023520

43 Sege R, Nykiel-Bub L, Selk S. Sex Differences in Institutional Support for Junior Biomedical Researchers. JAMA 2015;314:1175-7. doi:10.1001/jama.2015.8517

44 Oliveira DFM, Ma Y, Woodruff TK, Uzzi B. Comparison of National Institutes of Health Grant Amounts to First-Time Male and Female Principal Investigators. JAMA 2019;321:898-900. doi:10.1001/ jama.2018.21944

45 Jagsi R, Griffith KA, Jones R, Perumalswami CR, Ubel P, Stewart A. Sexual Harassment and Discrimination Experiences of Academic Medical Faculty. JAMA 2016;315:2120-1. doi:10.1001/ jama.2016.2188

46 Carr PL, Ash AS, Friedman RH, et al. Faculty perceptions of gender discrimination and sexual harassment in academic medicine. Ann Intern Med 2000;132:889-96. doi:10.7326/0003-4819-132-11200006060-00007

47 Sarsons H. Interpreting Signals in the Labor Market: Evidence from Medical Referrals. [Job Market Paper] Harvard University, 2017.

Supplementary information: figures S1 and S2 and tables S1-S10 